\title{
Research of the Reinforcing Fillers Influence on Mechanical Properties of the Cement Compound
}

\author{
Dmitriy A. Prikhodov*a,b, \\ Eleonora M. Nikiforovab ${ }^{b}$ and Alexander F. Shimanskiy ${ }^{b}$ \\ ${ }^{a}$ Radiochemical plant Mining and Chemical Combine \\ 53 Lenin Str., Zheleznogorsk, 662972, Russia \\ ${ }^{b}$ Siberian Federal University \\ 79 Svobodny, Krasnoyarsk, 660041, Russia
}

Received 05.07.2017, received in revised form 17.09.2017, accepted 06.05.2018

Long-term and safe management of radioactive wastes, that was formed as a result of implementation of nuclear weapon programs, still remains a key problem of the nuclear energetics. The technology based on the admixture of liquid radioactive wastes in inorganic hydraulic binders (cementation process) has a number of cogent advantages: the process is of low-temperature, it proceeds without formation of gaseous radioactive wastes and the obtained cement compound provides the safety storage for a long time (more than $10^{6}$ years). For the purpose to increase the degree of the cement compound filling with the liquid radioactive wastes, the possibility to apply reinforcing fillers was researched, this fillers are multilayered carbon nanotubes (MCNT) and pyrogenic silica (aerosil). It has been revealed that the proportion of MCNT should not exceed 1.5\% by weight of the cement content and the aerosil proportion should not exceed $0.5 \%$ of the binder weight. The maximal positive effect of admixture of MCNT to the compounds composition is achieved by injecting them with mixing water that contain $0.44 \%$ by mass of surface-active substances (SAS).

Keywords: radioactive waste, cement compound, multilayered carbon nanotubes, aerosil.

Citation: Prikhodov D.A., Nikiforova E.M., Shimanskiy A.F. Research of the reinforcing fillers influence on mechanical properties of the cement compound, J. Sib. Fed. Univ. Eng. technol., 2018, 11(5), 567-577. DOI: 10.17516/1999-494X-0055.

(C) Siberian Federal University. All rights reserved

* Corresponding author E-mail address: pramid1985@mail.ru 


\title{
Исследование влияния армирующих наполнителей
}

\section{на механические свойства цементного компаунда}

\author{
Д.А. Приходов ${ }^{\mathrm{a}, \boldsymbol{\sigma}}$, Э.М. Никифорова ${ }^{\tilde{\sigma}}$, А.Ф. Шиманский ${ }^{\tilde{\sigma}}$ \\ ${ }^{a}$ Радиохимический завод Горно-химического комбината \\ Россия, 662972, Железногорск, ул. Ленина, 53 \\ ${ }^{6}$ Сибирский федеральный университет \\ Россия, 660041, Красноярск, пр. Свободный, 79
}

\begin{abstract}
Долговременное безопасное обращение с радиоактивными отходами, образовавщимися в результате выполнения ядерных оружейных программ, остается ключевой проблемой для ядерной энергетики на современном этапе. Технология, основанная на включении жидких радиоактивных отходов в неорганические гидравлические вяжущие (процесс иементирования), имеет ряд неоспоримых преимуществ: прочесс является низкотемпературным, протекает без образования газообразных радиоактивных отходов, а полученный цементный компаунд обеспечивает безопасность хранения в течение длительного времени (более $10^{6}$ лет). С иелью увеличения степени наполнения цементного компаунда жидкими радиоактивными отходами исследована возможность применения армирующих наполнителей-многослойных углеродных нанотрубок (МУНТ) и пирогенного кремнезема (аэросила). Установлено, что дозировка МУНТ не должна превышать 1,5\% масс. от содержания иемента, аэросила - 0,5\% масс. от вяжущего. Максимальный положительный эффект от добавления в состав компаундов МУНТ достигается при введении их с водой затворения, содержащей 0,44 \% масс. поверхностноактивных веществ (ПАВ).
\end{abstract}

Ключевые слова: радиоактивные отходы, цементный компаунд, многослойные углеродные нанотрубки, аэросил.

\section{Введение}

Концепция вывода из эксплуатации ядерных и радиационно опасных объектов предполагает обязательное кондиционирование, иммобилизацию и захоронение всех накопленных радиоактивных отходов (РАО). Краткосрочные задачи обращения с РАО, такие как удаление низкоактивных и среднеактивных отходов, промежуточное хранение отходов всех категорий, в настоящее время решаются эффективно и безопасно. Главной проблемой остается долговременное обращение с высокоактивными РАО, образованными от переработки отработавшего ядерного топлива. В настоящее время в мире накоплен значительный объем жидких высокоактивных РАО с суммарной активностью в резервуарах хранения $10^{7} \div 10^{8}$ ТБк [1]. Длительное хранение жидких высокоактивных РАО приводит к накоплению твердого осадка (пульпы). Именно эта форма отходов является наиболее сложной при кондиционировании и иммобилизации [2].

Пульпу необходимо перерабатывать с целью извлечения таких компонентов, как уран, плутоний и других актиноидов $\left({ }^{241} \mathrm{Am},{ }^{244} \mathrm{Cm},{ }^{237} \mathrm{~Np}\right)$, и возврата регенерированных материалов в ядерный топливный цикл. Сложная и переменная консистенция пульпы не позволяет существующим технологиям полностью извлекать $\alpha$-активные радионуклиды из её состава, в связи с чем часть радионуклидов остается в пульпе [3]. Труднорастворимые остатки радиоактивной пульпы с неизвлечёнными $\alpha$-излучающими радионуклидами подлежат надежной изоляции. 
Для долговременной $\left(10^{4} \div 10^{5}\right.$ лет) изоляции труднорастворимых остатков радиоактивной пульпы высокоактивных РАО, содержащих $\alpha$-излучающие радионуклиды, наиболее надежным способом кондиционирования является их иммобилизация в неорганические матрицы (стекло, керамика, минералоподобные композиции и цементные компаунды) [1].

В мировой практике цементная матрица, с успехом используемая для иммобилизации жидких среднеактивных РАО, для отверждения высокоактивных РАО долгое время не применялась. Впервые в опытном масштабе в лаборатории Саванна Ривер (США) была изучена возможность включения оружейных высокоактивных РАО в цемент. В дальнейшем метод получил своё развитие в Окриджской Национальной Лаборатории (США), где был разработан способ получения цементной матрицы методом горячего прессования FUETAP-процесс (FUETAP Formed Under Elevated Temperatures And Pressures) [4].

Эффективность портландцемента определяется его способностью сохранять щелочную среду поровой жидкости в течение более $10^{6}$ лет [4]. Выщелачивание актиноидов (переход их в контактирующую с цементным компаундом водную среду) определяется растворимостью соединений актиноидов в цементной матрице. В щелочной среде поровой воды портландцементной матрицы поддерживаются условия для низкой растворимости соединений актиноидов (например, по данным [5], растворимость соединений плутония в щелочной среде очень мала и составляет $\left.2,71 \cdot 10^{-7} \mathrm{мг} / л\right)$.

Включение труднорастворимых остатков радиоактивной пульпы в цементную матрицу позволяет перевести жидкие радиоактивные отходы в форму, пригодную для долговременной изоляции (иммобилизация РАО), и снизить радиоактивность отходов за счет дозированного включения РАО в матрицу и создания дополнительной биологической защиты, роль которой выполняет цементная матрица. Конечный продукт процесса цементирования (цементный компаунд) должен быть отнесен к категории твердых радиоактивных отходов.

Для уменьшения количества образования данных вторичных радиоактивных отходов (твердых РАО) необходимо решить вопрос максимального наполнения радиоактивными пульпами цементного компаунда без снижения его механических свойств ниже регламентированных значений.

Степень наполнения цементного компаунда радиоактивной пульпой ограничена долей вяжущего в компаунде. С увеличением степени наполнения радиоактивной пульпой доля вяжущего снижается. В результате разбавления цементного камня происходит уменьшение зон контакта между гранулами цементного клинкера и заполнителем (пульпой), что приводит к снижению механической прочности компаунда ниже 5 МПа. Применение различных пластифицирующих добавок и сорбентов приводит к дополнительному разбавлению цементного камня и, следовательно, к еще большему уменьшению доли вяжущего в компаунде.

В качестве рабочей гипотезы для увеличения степени наполнения цементного компаунда пульпой предложено применение армирующих наполнителей, массовая доля которых незначительна (в пределах десятых долей процентов от содержания вяжущего).

В работах, посвященных изучению свойств модифицированного бетона, отмечено, что добавление углеродных частиц наноразмерного уровня в количестве $0,001 \div 0,5 \%$ масс. от содержания вяжущего приводит к значительному повышению прочностных характеристик бетонов [6-9].

$$
-569-
$$


Для подтверждения выдвинутой рабочей гипотезы исследований была изучена возможность применения в качестве армирующего наполнителя цементного компаунда многослойных углеродных нанотрубок (МУНТ) и пирогенного кремнезема (аэросила).

Нанотрубкам углерода свойственна высокая прочность. Модуль Юнга достигает значения в 1,28 $\div 1,8$ ТПа [10], что в 10 раз превышает данный показатель для стали.

Аэросил - искусственные микроаморфные безводные частицы кремнезема $\mathrm{SiO}_{2}$, не загрязнен большим количеством примесей. Наличие в нем аморфного диоксида кремния с характером ультрадисперсных частиц позволяет отнести аэросил к суперпуццоланам [11]. Дозировка вводимого микрокремнезема во многих случаях колеблется в широких пределах - от доли до нескольких десятков процентов от массы вяжущего вещества $[12,13]$.

\section{Материалы и методы исследования}

Для получения высокопрочных бетонов с высокими показателями водонепроницаемости в нормальных условиях твердения к цементам предъявляются особые требования: содержание $\mathrm{C}_{3} \mathrm{~S}$ должно быть в пределах 49-60 \% масс., $\mathrm{C}_{3} \mathrm{~A}$ - менее $10 \%$ масс., $\mathrm{C}_{4} \mathrm{AF}$ - не более $15 \%$ масс., удельная поверхность - порядка $280 \div 350 \mathrm{~m}^{2} /$ кг [14]. На основании данных ограничений предложено использование цемента серийного производства марки ПЦ-500Д0.

Для приготовления цементных компаундов использовали следующие вяжущие материалы и добавки: портландцемент СЕМ I 42,5Н ГОСТ 30515-2013, суперпластификатор С-3 ТУ5870004-46849456-04, многослойные углеродные нанотрубки DEALTOM TУ2166-001-883208472014, аэросил марки А-175 ГОСТ 14922-77.

Главное преимущество нанотрубкок DEALTOM (рис. 1) относительно выпускаемых углеродных нанотрубок других производителей (как отечественных, так и импортных) состоит в отсутствии примесных элементов (сера, хлор, фосфор, азот), что позволяет создавать композиты с заданными физико-механическими свойствами. Их синтезируют по методу низкотемпературного термокаталитического пиролиза углеводородов, позволяющего создавать углеродные нанотрубки низкой себестоимости [15].

Аэросил марки А-175 обладает удельной поверхностью частиц $175 \mathrm{~m}^{2} / \Gamma$ и средним размером частиц 12 нм.

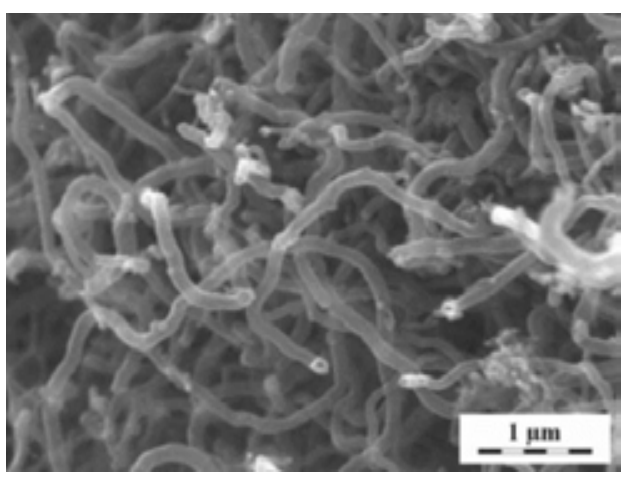

Рис. 1. Углеродные многослойные нанотрубки DEALTOM

Fig. 1. Multilayer carbon nanotubes "DEALTOM" 


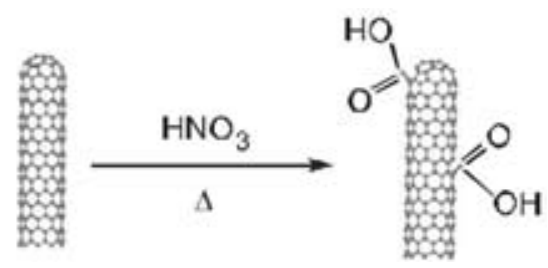

Рис. 2. Активирование МУНТ в азотной кислоте

Fig. 2. MCNT activated with nitric acid

Изготовленные образцы цементных компаундов отличались содержанием армирующих наполнителей (0,5-1,5-2,5 \% от содержания цемента) и способом их диспергирования в объеме цементного компаунда, а именно наличием поверхностно-активного вещества (ПАВ) либо его отсутствием. Кроме того, для МУНТ было изучено влияние предварительного химического активирования. Для обеспечения сопоставимости результатов изготовлены по три образца каждого состава компаундов.

Для изготовления образцов цемент загружали в мерные емкости, куда добавляли расчетный объем воды затворения, содержащий выбранные добавки в заданном соотношении. Полученную смесь тщательно перемешивали до получения однородного состава и помещали в специально изготовленные формы из фторопласта. В соответствии с утвержденной отраслевой методикой измерения ОИ001.725-2011 «Цементные компаунды на основе радиоактивных отходов. Определение предела прочности на сжатие» размер образцов цементного компаунда установлен диаметром и высотой 20 мм.

Путем легкого постукивания по корпусу форм в течение нескольких минут смесь уплотняли и удаляли из нее воздух. После этого формы помещали на 24 ч в камеру нормального твердения, обеспечивающую при температуре $20 \pm 3{ }^{\circ} \mathrm{C}$ относительную влажность воздуха $95 \pm 5 \%$. Через сутки образцы извлекали из форм и помещали их обратно в камеру нормального твердения на 28 сут. Испытания механической прочности на сжатие производили после истечения 28 сут твердения.

В работах $[8,16]$ отмечено, что для реализации упрочняющего эффекта углеродных нанотрубок необходимо создавать высокую адгезию поверхности нанотрубок к гидрофильной матрице бетона. Решение данной задачи может быть достигнуто за счет поверхностной модификации (активирования) углеродных нанотрубок, обеспечивающей образование на поверхности углеродной нанотрубки функциональных полярных групп.

Для активирования исходные наноматериалы были выдержаны в пятимолярном растворе азотной кислоты (рис. 2) в соотношении 1:1 в течение 2 ч. После выпаривания кислоты осадок МУНТ был промыт водой, отфильтрован и высушен.

Испытания на механическую прочность на сжатие образцов проводили на гидравлическом прессе ВМ-3,4 с предельной нагрузкой до 500 кН и погрешностью измерения $\pm 1 \%$.

\section{Результаты экспериментов и их обсуждение}

Исследованные составы цементного раствора корректировали исходя из оценки растекаемости (пластичности) пробного замеса. Растекаемость является одной из основных технологи- 
ческих характеристик качества цементного теста. Для обеспечения хорошего смешивания компонентов компаунда, перемешивания смеси и равномерного заполнения цементным раствором контейнера растекаемость цементного компаунда не должна превышать 200 мм. Оптимален

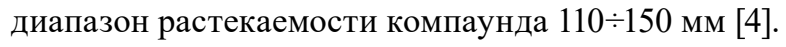

В табл. 1 приведены составы цементных компаундов и результаты их испытаний на механическую прочность с добавлением МУНТ без предварительного активирования и после проведения химического активирования (азотнокислого спекания).

Для изучения влияния способа диспергирования МУНТ с помощью ПАВ и механического перемешивания в воде затворения были приготовлены образцы, в которых в качестве ПАВ использовали суперпластификатор С-3.

Зависимость механической прочности на сжатие от содержания МУНТ и способа его диспергирования в цементном компаунде представлена на рис. 3.

Установлено, что добавка суперпластификатора С-3 увеличивает механическую прочность компаундов за счет взаимодействия молекул ПАВ с ионами кальция на поверхности зерен цемента и образования поверхностной пленки соединения типа $-\mathrm{Si}-\mathrm{O}-\mathrm{Ca}-\mathrm{SO}_{3} \mathrm{R}$. Данная пленка приводит к снижению внутреннего трения в бетонной смеси. Кроме того, добавка обладает пептизирующим действием, которое препятствует образованию флоккул из цементных частиц в процессе гидратации, что в свою очередь приводит к увеличению удельной поверхности частиц и оказывает положительное влияние на интенсивность процессов гидратации и структурообразования цементного камня $[6,8]$.

Прирост прочности компаунда только за счет введения пластифицирующей добавки для образцов без добавления МУНТ составил 33,3 \%, максимальный прирост механической прочности компаундов за счет введения наномодификатора - 37,2 \% при содержании нанодобавки

Таблица 1. Составы, технологические характеристики бетонных смесей и физико-механические свойства бетонов

Table 1. Compositions, technological characteristics of concrete mixtures, physical and mechanical properties of concretes

\begin{tabular}{|c|c|c|c|c|c|c|c|c|}
\hline \multirow{2}{*}{$\begin{array}{l}\text { Образец } \\
\text { № }\end{array}$} & \multicolumn{4}{|c|}{ Состав смеси, \% масс. } & \multirow{2}{*}{$\begin{array}{c}\text { Содержание } \\
\text { МУНТ, \% масс. } \\
\text { от вяжущего }\end{array}$} & \multirow{2}{*}{ В/Ц } & \multirow{2}{*}{$\begin{array}{c}\text { Растекаемость } \\
\text { бетонной } \\
\text { смеси, мм }\end{array}$} & \multirow{2}{*}{$\begin{array}{l}\text { Прочность на } \\
\text { сжатие, МПа }\end{array}$} \\
\hline & ПЦ & Вода & $\mathrm{C}-3$ & МУНТ & & & & \\
\hline 1 & 68,18 & 31,82 & - & - & - & 0,47 & 150 & 15,6 \\
\hline 2 & 67,95 & 31,71 & - & 0,33 & 0,5 & 0,47 & 150 & 16,9 \\
\hline 3 & 66,00 & 33,01 & - & 0,99 & 1,5 & 0,5 & 150 & 21,4 \\
\hline 4 & 64,17 & 34,23 & - & 1,60 & 2,5 & 0,53 & 150 & 13,8 \\
\hline 5 & 67,95 & 31,71 & - & 0,33 & 0,5 & 0,47 & 180 & 15,9 \\
\hline 6 & 67,87 & 31,68 & 0,45 & - & - & 0,47 & 180 & 20,8 \\
\hline 7 & 67,64 & 31,58 & 0,45 & 0,33 & 0,5 & 0,47 & 150 & 24,2 \\
\hline 8 & 65,72 & 32,85 & 0,44 & 0,99 & 1,5 & 0,5 & 150 & 24,5 \\
\hline 9 & 63,91 & 34,06 & 0,43 & 1,60 & 2,5 & 0,53 & 150 & 19,3 \\
\hline 10 & 67,64 & 31,58 & 0,45 & 0,33 & 0,5 & 0,47 & 220 & 22,4 \\
\hline
\end{tabular}

Примечание: в образцах № 5, 10 исследован химически активированный МУНТ. 


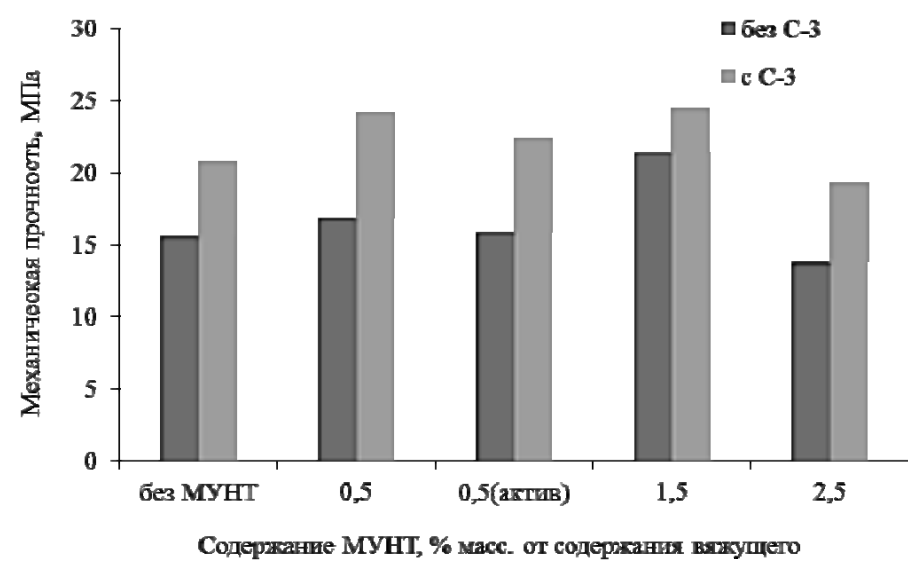

Рис. 3. Механическая прочность образцов цементного компаунда в зависимости от содержания МУНТ

Fig. 3. Mechanical strength of cement compound samples depending on the content of MCNT

1,5 \% масс. от содержания цемента. Максимальный синергетический эффект от добавления в компаунд суперпластификатора C-3 и углеродных нанотрубок DEALTOM равнялся 57 \%. Данный положительный эффект отмечен для образцов, в состав которых введены МУНТ (1,5 \% масс. от вяжущего) с водой затворения, содержащей $0,44 \%$ масс. суперпластификатора C-3.

Выявлен незначительный эффект предварительного химического активирования МУНТ при их малых дозировках. Так, прирост прочности для образцов с содержанием МУНТ 0,5 \% масс. от вяжущего составил 1,9-7,7 \%.

При таких малых дозировках МУНТ механизм их модифицирования не связан с химическим взаимодействием с составляющими цементной пасты. Необходимо, прежде всего, учитывать поверхностные явления, возникающие при введении нанотрубок.

Механизм модифицирования можно объяснить следующим процессом. Ионы $\mathrm{Ca}^{2+}$, образующиеся в результате диссоциации клинкерных фаз цемента, осаждаются на поверхности нанотрубок и взаимодействуют с образованными гидроксид- и силикатионами, формируя при этом центры кристаллизации гидратных новообразований $[17,18]$. Процесс формирования новообразований протекает интенсивно, так как концентрирование ионов $\mathrm{Ca}^{2+}$ на поверхности нанотрубок приводит к реализации условия для роста кристаллов портландита и других аморфных гидросиликатов кальция. Необходимо, чтобы содержание ионов $\mathrm{Ca}^{2+}$ в местах формирования новообразований превышало концентрацию насыщенного раствора в 1,5-2 раза. Структурные новообразования на поверхности углеродных нанотрубок формируют плотный высокопрочный пространственный каркас, объединяющий все компоненты компаунда в конгломерат с улучшенными физико-техническими свойствами.

Однако при превышении оптимального значения концентрации нанотрубок углерода (более 1,5 \% масс. от содержания портландцемента) наблюдается постепенное падение прочности. Данное «разупрочнение» может быть объяснено двумя причинами: дефицитом вяжущего для высокоразвитой поверхности углеродных нанотрубок и невозможностью обеспечения равномерного распределения нанотрубок в объеме компаунда на стадии механического перемеши-

$$
-573-
$$


вания. В результате снижается сцепление между частицами вяжущего и наполнителя. При дозировках МУНТ более 1,5 \% масс. от содержания цемента требуется применение специальных технологий по их диспергированию (ультразвуковое, кавитационное и т.д.), но высокая энергоемкость и малая производительность данных процессов существенно затрудняет их применение в рамках реального производства [19].

Применение аэросила для повышения механических характеристик компаунда также весьма перспективно вследствие связывания им выделяющейся при гидратации цемента свободной извести по реакции [11]:

$$
\mathrm{xCa}(\mathrm{OH})_{2}+\mathrm{SiO}_{2}+\mathrm{yH}_{2} \mathrm{O} \rightarrow(0,8 \div 1,5) \mathrm{CaO} \cdot \mathrm{SiO}_{2} \cdot \mathrm{zH}_{2} \mathrm{O} .
$$

Новообразования типа $(0,8 \div 1,5) \mathrm{CaO} \cdot \mathrm{SiO}_{2} \cdot(0,5 \div 2,5) \mathrm{H}_{2} \mathrm{O}$ принято относить к гидросиликатам кальция первого вида C-S-H (I). Гидросиликаты этого вида являются низкоосновными $\left(\mathrm{CaO}: \mathrm{SiO}_{2}<1,5\right)$ и характеризуются повышенными прочностными показателями вследствие высокой степени конденсации кремнекислородных анионов. В данном случае система обогащается элементами с более прочными ковалентными (силоксановыми $\mathrm{Si}-\mathrm{O}-\mathrm{Si}$ ) связями, создающими предпосылки к развитию высокой прочности. Вклад ковалентных связей в прочность бетона составляет около 65 \% [20]. Присутствие данных гидратных новообразований в структуре цементного компаунда весьма желательно.

Составы бетонных смесей с добавлением аэросила и результаты механической прочности на сжатие бетонов на их основе представлены в табл. 2.

На рис. 4 показана зависимость механической прочности на сжатие образцов цементного компаунда от содержания аэросила и наличия ПАВ.

Максимальный прирост прочности (18 \%) отмечен для образцов, содержащих аэросил в количестве 0,5 \% масс. в цементе. При этом, как следует из рис. 4 , добавление суперпластификатора С-3 не влияет на прочность компаундов, содержащих аэросил.

Таблица 2. Составы, технологические характеристики бетонных смесей и физико-механические свойства бетонов

Table 2. Compositions, technological characteristics of concrete mixtures, physical and mechanical properties of concretes

\begin{tabular}{|c|c|c|c|c|c|c|c|c|}
\hline \multirow{2}{*}{$\begin{array}{c}\text { Образец } \\
\text { № }\end{array}$} & \multicolumn{4}{|c|}{ Состав смеси, \% масс. } & \multirow{2}{*}{$\begin{array}{c}\text { Содержание } \\
\text { аэросила, } \\
\text { \% масс. } \\
\text { от вяжущего }\end{array}$} & \multirow{2}{*}{ В/Ц } & \multirow{2}{*}{$\begin{array}{l}\text { Растекаемость } \\
\text { смеси, мм }\end{array}$} & \multirow{2}{*}{$\begin{array}{l}\text { Прочность на } \\
\text { сжатие, МПа }\end{array}$} \\
\hline & ПЦ & Вода & $\mathrm{C}-3$ & Аэросил & & & & \\
\hline 1 & 68,18 & 31,82 & - & - & - & 0,47 & 150 & 15,6 \\
\hline 2 & 66,45 & 33,22 & - & 0,33 & 0,5 & 0,5 & 120 & 18,4 \\
\hline 3 & 59,47 & 39,64 & - & 0,89 & 1,5 & 0,67 & 140 & 12,6 \\
\hline 4 & 52,86 & 45,82 & - & 1,32 & 2,5 & 0,87 & 180 & 9,0 \\
\hline 5 & 67,87 & 31,68 & 0,45 & - & - & 0,47 & 180 & 20,8 \\
\hline 6 & 64,72 & 34,52 & 0,43 & 0,33 & 0,5 & 0,53 & 180 & 18,1 \\
\hline 7 & 60,44 & 38,27 & 0,40 & 0,89 & 1,5 & 0,63 & 190 & 13,4 \\
\hline 8 & 55,68 & 42,63 & 0,37 & 1,32 & 2,5 & 0,77 & 200 & 9,0 \\
\hline
\end{tabular}




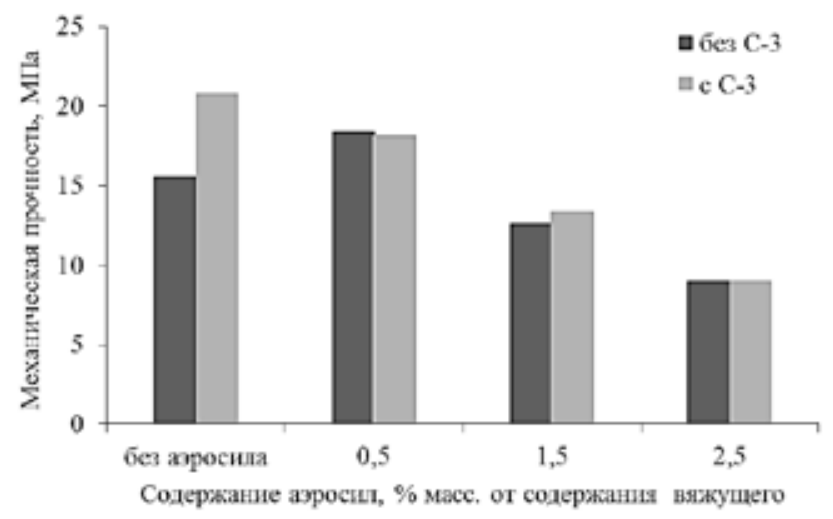

Рис. 4. Механическая прочность образцов цементного компаунда в зависимости от содержания аэросила

Fig. 4. Mechanical strength of samples of cement compound depending on the content of aerosil
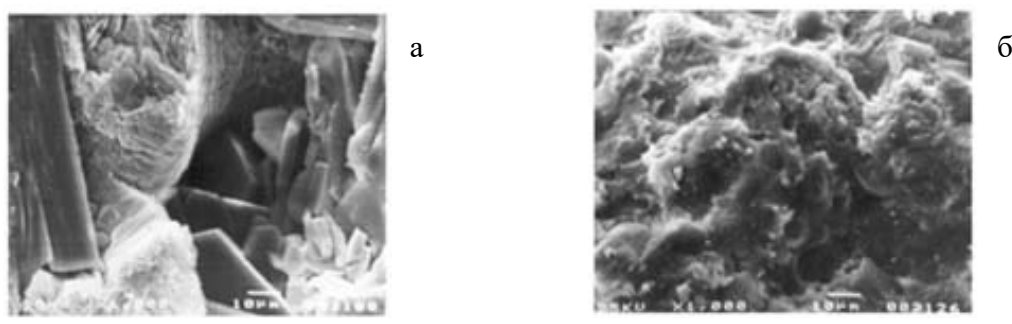

Рис. 5. Электронно-микроскопические фотографии цементной пасты: а - без аэросила; б - с аэросилом

Fig. 5. Electron microscopic photos of cement paste: a - without aerosol; $\sigma$ - with aerosil

Дальнейшее снижение прочности с повышением концентрации аэросила (рис. 4) связано с повышением В/Ц соотношения в системах (табл. 2). При суспендировании частиц аэросила в воде происходят химические реакции с образованием гидрогеля, способного долгое время удерживать влагу, но для его подвижности необходимо увеличивать расход воды.

Для модифицированных аэросилом цементных систем отмечено, что в процессе гидратации крупные кристаллы портландита (пластины) практически не видны, они слишком малы или плохо сформированы и находятся за пределами разрешающей способности сканирующего электронного микроскопа (рис. 5).

Портландит, образованный в процессе гидратации алита и белита соединился с частицами аэросила, в результате чего образовались низкоосновные гидросиликаты кальция.

\section{Выводы}

Для увеличения степени наполнения цементного компаунда пульпой рекомендовано использование в качестве армирующего наполнителя многослойных углеродных нанотрубок (МУНТ) и пирогенного кремнезема (аэросил). При этом дозировка МУНТ не должна превышать 1,5 \% масс. от содержания цемента. Оптимальное содержание аэросила в вяжущем соответствует $0,5 \%$ масс. 
Для максимального повышения прочности цементных компаундов необходимо углеродные нанотрубки вносить в цементную систему с водой затворения, содержащей 0,44 \% масс. суперпластификатора С-3.

Целесообразно продолжение исследований по подбору состава цементного компаунда для отверждения реальной радиоактивной пульпы с использованием в качестве армирующего наполнителя МУНТ и аэросила, в том числе испытаний на скорость выщелачивания, морозостойкость и устойчивость к длительному пребыванию в воде.

Ожидаемый положительный результат от применения МУНТ и аэросила для отверждения реальных радиоактивных пульп позволит сократить образование вторичных ТРО до 5 раз за счет увеличения степени наполнения каждого компаунда без снижения его качества.

\section{Список литературы}

[1] Василенко В.А., Ефимов А.А., Епимахов В.Н. Обращение с радиоактивнылми отходами в России и странах с развитой атомной энергетикой. СПб.: ООО «НИЦ «Моринтех»», 2005, 304 c. [Vasilenko V.A., Yefimov A.A., Epimakhov V.N. The management of radioactive waste in Russia and countries with developed nuclear power. SPb.: OOO "NIC "Morintekh"”, 2005, 304 p. (in Russian)].

[2] Кулагин В.А., Кулагина Т.А., Матюшенко А.И. Переработка отработавшего ядерного топлива и обращение с радиоактивными отходами. Журнал СФУ. Техника и технологии, 2013, 6(2), 123-149 [Kulagin V.A., Kulagina T.A., Matushenko A.I. Spent Fuel Reprocessing and Radioactive Waste Management, J. Sib. Fed. Univ. Eng. Technol, 2013, 6(2), 123-149 (in Russian)].

[3] Ермолаев В.М., Захарова Е.В., Мироненко М.В. Изменение состава и свойств радиоактивных пульп в процессе длительного хранения в емкостях. Радиохимия, 2006, 48(3), 301-306 [Ermolaev V.M., Zaharova E.V., Mironenko M.V. Evolution of composition and properties of radioactive pulps in long-term storage in tanks, Radiochemistry, 2006, 48(3), 301-306 (in Russian)].

[4] Ojovan M.I. Handbook of advanced radioactive waste conditioning technologies. Woodhead Publishing Limited, 2011, 488 p.

[5] Brown D.J., Lee D.J., Price M.S.T. Cement-based processes for the immobilization of intermediate level radioactive waste, Proceedings of the conference "Radioactive waste management", London: British Nuclear Energy Societies, 1984, 145-152.

[6] Лесовик Р.В., Глаголев Е.С., Савин А.В. Структурные возможности повышения качества бетонов для монолитного строительства. Вестник БГТУ им. В.Г. Шухова, 2009, 4, 39-42 [Lesovik R.V., Glagolev E.S., Savin A.V. Structural opportunities for improving the quality of concrete for monolithic construction. BGTU bulletin of V.G. Shukhov, 2009, 4, 39-42 (in Russian)].

[7] Хрусталев Б.М., Леонович С.Н., Якимович Б.А. Дисперсии многослойных углеродных нанотрубок в строительном материаловедении. Наука и техника, 2014, 1, 44-52 [Khrustalyov B.M., Leonovich S.N., Yakimovich B.A. Dispersion of multi-walled carbon nanotubes in building science of materials. Science and technology, 2014, 1, 44-52 (in Russian)].

[8] Хозин В.Г., Старовойтова И.А., Майсурадзе Н.В. Наномодифицирование полимерных связующих для конструкционных композитов. Строительные материаль, 2013, 2, 4-10 [Khozin V.G., Starovoitova I.A., Maisuradze N.V. Nanomodification of polymer binders for constructional composites. Construction Materials, 2013, 2, 4-10 (in Russian)]. 
[9] Черкасов Д.В. Портландиементы с добавкой модифицированных диатомитов и композиты на их основе. Саранск, 2014, 176 c. [Cherkasov D.V. Portlandcementy s dobavkoj modificirovanny diatomitov i kompozity na ih osnove. Saransk, 2014, 176 p. (in Russian)].

[10] Advani G. Suresh. Processing and properties of nanocomposites. World Scientific Publishing Co. Pte. Ltd., 2007, 463 p.

[11] Лукутцова Н.П., Пыкин А.А. Теоретические и технологические аспекты получения микро- и нанодисперсных добавок на основе шунгитосодержащих пород для бетона. Брянск: Изд-во БГИТА, 2013, 231 с. [Lukutcova N.P., Pykin A.A. Theoretical and technological aspects of obtaining micro- and nanodispersed additives based on shungite-bearing rocks for concrete. Bryansk: Izd-vo BGITA, 2013, 231 p. (in Russian)].

[12] Бердов Г.И., Ильина Л.В., Зырянова В.Н. Повышение свойств композиционных строительных материалов введением минеральных микронаполнителей. Строй-Профи: Бетоны, 2012, 2, 26-29 [Berdov G.I., Ilyina L.V., Zyryanova V.N. Increasing properties of composite building materials by the introduction of mineral microfillers. Stroy-Profi: Concrete, 2012, 2, 26-29 (in Russian)].

[13] Чепурная С.Н., Золотов М.С., Волювач С.В. Влияние тонкодисперсного мела на физико-механические показатели бетона, Труды 6-й Международной конференции «Архитектура, строительство - современность», Варна, 2013, 81-90; http://eprints.kname.edu.ua/36310/ Чепурная Болгария.pdf [Chepurna S.N., Zolotov M.S., Voluvach S.V. The influence of fine-disperse chalk on physical and mechanic indices of concrete, Proceedings of $6^{\text {th }}$ International Conference “Architecture, Civil, Engineering - Modernity", Varna, 2013, 81-90; http://eprints.kname.edu.ua/36310/ Чепурная Болгария.pdf (in Russian)].

[14] Баженов Ю.М. Технология бетона. Москва: АСВ, 2002, 500 c. [Bazhenov Y.M. Technology of concrete. Moskva: ASV, 2002, 500 p. (in Russian)].

[15] DEALTOM углеродные наноматериалы [Электронный ресурс]. M., 2008-2017. URL: http://www.dealtom.ru (дата обращения 30.01.2017).

[16] Мазов И.Н., Ильиных И.А., Кузнецов Д.В. Разработка методов получения модификаторов на основе углеродных нанотрубок для композиционных бетонов. Современные проблемы науки и образования, 2013, 5, 79-81 [Mazov I.N., Ilinykh I.A., Kuznetsov D.V. Synthesis of carbon nanotube-based modifiers composite concrete. Modern problems of science and education, 2013, 5, 79-81 (in Russian)].

[17] Cwirzen A., Habermehl-Cwirzen K., Shandakov D. Properties of high yield synthesised carbon nano fibres/Portland cement composite. Advances in Cement Research, 2009, 21, 141-146.

[18] Nasibulin A.G. A novel cement-based hybrid material. New Journal of Physics, 2009, 11, $1-11$.

[19] Гусев Б.В., Юдаев В.Ф. Механизм кавитационной активации цемента. Строительные материаль, оборудование, технологи ХХІ века, 2003, 6, 24-25 [Gusev B.V., Yudaev V.F. Mechanism of cavitation activation of cement. Construction materials, equipment, technologies of the $21^{\text {st }}$ century, 2003, 6, 24-25 (in Russian)].

[20] Брыков А.С. Гидратация портландиемента. СПб.: СПбГТИ(ТУ), 2008, 30 с. [Brykov A.S. Hydration of Portland cement. SPb.: SPbGTI(TU), 2008, 30 p. (in Russian)].

$$
-577-
$$

